\title{
TOPIC: Knowledge, Screening and Reporting Practices of Health Professionals towards Gender Based Violence among Women in Kabwe District, Zambia
}

\begin{tabular}{c} 
Jennipher Akebu N. Soko*, Cath \\
\hline School of Nursing Sciences, Uni \\
Article History \\
Received: 18.08 .2020 \\
Accepted: 03.09 .2020 \\
Published: 14.10 .2020 \\
Journal homepage: \\
https://www.easpublisher.com/
\end{tabular}

\section{rine Mubita Ngoma}

School of Nursing Sciences, University of Zambia, Lusaka

\section{Article History}

Received: 18.08 .2020

Accepted: 03.09.2020

Journal homepage:

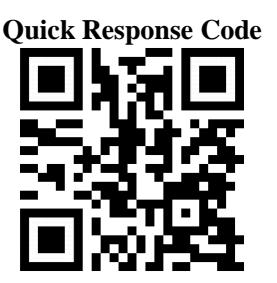

Abstract: Gender based violence is a major public health concern. The main aim of this study was to examine Knowledge, Screening and Reporting practices of Health Professionals towards gender based violence among women in Kabwe District, Zambia. This was a descriptive cross section study conducted in health facilities in Kabwe district. About 207 doctors, Nurse Midwives and Clinical Officers were selected to participate in the study using stratified sampling method. Data was collected using a questionnaire and was entered into SPSS version 22. Chisquare test was used to determine associations between the variables. The statistical significance was set at $5 \%$ and confidence interval was set at 95\%. The findings showed that a high percentage, $81.2 \%$ of the Health professionals had not been trained or sensitized on GBV, 79.7\% of them had high level of knowledge on GBV. Slightly more than half, $54 \%$ of the Health professionals screened women for GBV, mostly upon suspicion for GBV (72.3\%), which is also known as selective screening. Few of the HPs screened women for GBV often, $17.5 \%$ and very often $(8.9 \%)$. The majority, $38.2 \%$ of the respondents indicated that they did not have a written institutional policy / protocol on how to screen for GBV while $30.4 \%$ did not know whether their institutions had one. Few of the HPs were very confident $(22.7 \%)$ or extremely confident, $5.3 \%$ that they could screen women for GBV. Overall, the HPs' screening practices for GBV were inadequate $(83.6 \%)$. A statistically significant relationship was observed between respondents' profession and their screening practices for GBV $(\mathrm{p}-0.020)$. About one third, $31.4 \%$ of the HPs report GBV to legal authorities using a variety of reporting types. Very few, $12.3 \%$ of the HPs report GBV to legal authorities often, and very often, (1.4\%). Overall, the Health Professionals' reporting practices of gender based violence were insufficient, (87\%). A statistically significant relationship was observed between respondents' knowledge level on GBV and reporting practices $(\mathrm{P}-0.121)$, training and reporting practices for GBV ( $\mathrm{p}-0.039$ ). Most of the respondents, $35.7 \%$ indicated that there was no institutional policy/protocol to guide them on how to report gender based violence to legal authorities and slightly over one third, 34,8\% of the HPs did not know if there was one. Very few, $24.2 \%$ of the participants reported that they were very confident or extremely confident, $7.2 \%$ that they could report GBV to legal authorities. There is need therefore for Ministry of Health to review and periodically disseminate updated written guidelines / protocols on GBV management on screening and reporting requirements for GBV by HPs to all health institutions to keep HPs abreast on current GBV management practices. The Ministry of Health and the General Nursing and Midwifery Council of Zambia should address the gaps identified in screening women for gender based violence by including in depth information on screening and reporting policies and requirements on GBV in the Nursing curriculum.

Keywords: Gender Based Violence, knowledge, Reporting, Screening.

Copyright $\odot 2020$ The Author(s): This is an open-access article distributed under the terms of the Creative Commons Attribution 4.0 International License (CC BY-NC 4.0) which permits unrestricted use, distribution, and reproduction in any medium for non-commercial use provided the original author and source are credited.

\section{INTRODUCTION}

Gender Based Violence $(\mathrm{GBV})$ is any physical, mental, emotional, social or economic abuse against a person because of that persons' gender and includes sexual or psychological harm or suffering to a person, threats of such acts, coercion or arbitrary deprivation of liberty, whether occurring in public or private life [1]. It is often known as Gender Based Violence because it evolves in part from women's subordinate status in society, although the term GBV also encompasses men (Ministry of Gender and Child Development, [2]. The World Bank [3] has cited GBV against women as a global pandemic that affects 1 in 3 women in their life time Furthermore, GBV is reported to be the most wide spread violations of human rights 
that includes physical, sexual, psychological, verbal and economic abuse, and cuts across boundaries of age, race, culture, wealth and geography (UN women [4]. As already alluded to, there are five main forms of abuse that women experience: physical, psychological, sexual, verbal and economic. Sexual abuse refers to using physical coercion to force participation in unwanted sex acts [5]. Economic abuse refers to utilization of money to undermine a woman's rights, for example, withholding money, questioning what the woman does with her money, denying medical aid or destroying property in the home whenever there some disagreement (Agisanang Domestic Abuse Prevention and Training [6]. Psychological violence refers to any act which causes psychological harm to an individual. Psychological violence can take the form of, for example, coercion, defamation, verbal insult or harassment [7]. Verbal abuse, also known as verbal attack or verbal assault refers to the act of forcefully criticizing, insulting, or denouncing another person. Physical abuse refers to any act which causes physical harm as a result of unlawful physical assault. Physical violence may take the form of serious and minor assault, deprivation of liberty and manslaughter (European Union Agency for Fundamental Rights [8].

Statistics reported by the World Bank are shocking; slightly above one third, 35\%, of women worldwide have experienced either physical and / or sexual intimate partner violence or non-partner sexual violence. Globally, as many as $38 \%$ of murders of women are committed by an intimate partner [3]. The patterns and consequences of GBV in men and women are different as women are more likely than men to be injured by someone close to them and they comprise the overwhelming majority of survivors of GBV [9]. Therefore GBV in this study was restricted to physical abuse of a woman by their intimate partner. An Intimate partner refers to a person with whom a woman has or had a close personal or sexual relationship. Intimate partner violence affects millions of women each year in the United States [10].

Zambia like any other country has not been spared by GBV. The Police Victim Support Unit recorded a total of 18088 country and Central province was ranked third with 2, 100 cases of GBV in 2015 [11]. Kabwe District has not been spared from the scourge of GBV in the form of physical abuse in women as cases remained persistently high for three consecutive years; Statistic shows that out of a total of 3, 204 cases of GBV in the form of physical abuse from an intimate partner, the majority, $86.3 \%, 86.8 \%$ and $88.5 \%$ in 2016, 2017 and 2019 respectively were females [12]. Gender based violence in the form of spousal physical abuse in women is prevalent and victims pass through health facilities to seek medical services for physical complaints related to the abuse suffered. Most likely, HPs might be the first and only point of contact to a formal sector outside the home for women experiencing GBV [13]. Therefore, it is cardinal for HPs who come in contact with women to play a critical role in prevention and responding to GBV by identifying any underlined physical abuse during history taking and physical assessment. This is in view of a background of silence where most victims do not disclose their experiences of GBV to HPs unless they are asked. Without screening for GBV, many cases may pass through the hands of HPs and health facilities unidentified [5]. This implies that the victims will not be linked to a comprehensive programme of multisectoral approach designed to mitigate the root causes of GBV in women. Blank and Rosslhumer [14] also acknowledge the importance of screening women for GBV in a professional and supportive manner as a means of breaking feelings of isolation, guilt and shame that victims of GBV may experience. Furthermore, screening women for GBV conveys the message that help is available [14]. Screening can be implemented routinely as part of history taking for all women seeking health care services or selectively. Selective screening is limited to high risk groups such as pregnant women and upon an index of suspicion for GBV.

The role of HPs in the management of victims of GBV does not end at screening and provision of medical services. Reporting GBV to legal authorities is another cardinal step closely related to screening for GBV. The National Crime research [15] cites failure to report GBV cases to law enforcement agency as one of the greatest barriers to prevention and control of GBV. Reporting of GBV to legal authorities such as the police facilitates prosecution of perpetrators and improves HPs' responsiveness [16]. Application of selective screening entails that HPs have knowledge of the magnitude, presentation of and the high risk groups for GBV. Therefore HPs are required to be knowledgeable of the referral system, protocols and available sources of social services including those outside the Health sector. Capacity building of HPs in the form of ongoing training / sensitization on GBV in general is necessary to enhance HPs with the knowledge and skills required to effectively manage victims of GBV. There are many barriers that hinder HPs from screening and reporting GBV to legal authorities. Controversial attitudes towards screening for GBV that undermine the medical response have been reported among HPs [17]. Hewins and Maula [18] also report that some of the HPs believe that it is not their role to screen for GBV.

The Government of the Republic of Zambia has made some progress in the fight against GBV and is determined to create a fairer and more equal society for all. This includes the establishment of fast track courts to deal with cases of Gender Based Violence. The Zambian government in partnership with USAID through the STOP-GBV project has conducted several training /sensitization workshops of police officers, magistrates, politicians, doctors, nurses and traditional leaders on what Gender Based Violence is, how to 
respond to it, and most importantly how to stop. This is in an effort to strengthen governmental and traditional leadership's commitment to GBV prevention and response, mobilizing communities for gender norms change, strengthening the capacity of legal and law enforcement systems to respond to GBV, and providing quality one-stop GBV response care [19]. The government of Zambia has also enacted the AntiGender Based Violence Act No. 1 of 2011 and the Penal Code Amendment Act No. 15 of 2005 to criminalize GBV and to stiffen penalties for sexual offences [20]. Identification of victims of physical abuse among women who seek health services is a challenge to HPs [14]. This challenge is attributed to low levels of knowledge on GBV, low rates of screening for GBV by HPs [21] and non-disclosure of GBV by victims. Further, reporting GBV to police or a relevant agency is a key step in the fight against GBV [22]. Yet victims of GBV and HPs are reluctant to report GBV to legal authorities even in nations where mandatory reporting laws exist (European Union Agency for Fundamental Rights (FRA) [8]. In Zambia, the knowledge, screening and reporting practices of HPs towards physical abuse in women is not clear as there is limited literature to support this. The researcher therefore sought to establish Health Professionals' knowledge levels, screening and reporting practices towards physical abuse in women in order to identify any gaps that needed to be addressed for HPs to make significant contributions towards the fight against GBV.

The purpose of the study was to examine the knowledge, screening and reporting practices of HPs towards GBV in women in Kabwe District with the aim of strengthening the best practices among HPs in the fight against GBV in women.This study is of great relevance to the Community, Ministry of Health, Health professional bodies and non-Governmental organisations dealing with GBV as it has given an insight on HPs knowledge, screening and reporting practices towards physical abuse in women. The findings of the current study provide a frame of reference upon which Ministry of Health $(\mathrm{MoH})$, Health professional bodies and Non-Governmental Organisations that deal with GBV can base their decisions to monitor, evaluate or revisit the protocols / policies on management of physical abuse in women and possibly plan staff training /sensitization programmes on GBV to improve the situation. The study laid a foundation for other researchers and added to the existing body of scientific knowledge by revealing the HPs levels of knowledge, screening and reporting practices towards physical abuse in women. The findings of the current study have provoked further questions and analysis calling for more research to establish factors contributing to insufficient screening and inadequate reporting practices of GBV to legal authorities despite the HPs having high levels of knowledge on GBV.

\section{METHODS}

This study was a cross-sectional descriptive study design conducted in six clinics and one hospital in Kabwe district, Central province of Zambia. The health facilities included Makululu, Kasanda, Railway, Katondo, Mahatma Gandi and Natuseko and Kabwe General hospital. Kabwe district is the provincial headquarters for the Central Province of Zambia. The district was selected due to persistently high cases of GBV in the form of spousal physical abuse. The clinics are situated right in the densely populated communities where GBV takes place and are important entry points for victims of GBV into a formal system that would link them to a comprehensive package of care that includes medical, counseling and legal services as required. The Central Province of Zambia consists of 12 districts and Kabwe is the Provincial headquarters. The District had seventeen Public Health Centers and eight clinics distributed under Ministry of Defence, Correctional Services and Home Affairs as well as the private sector respectively. Kabwe district was unique in terms of health care delivery in that the provincial district did not have a District hospital at the time of collecting data. It only had a General hospital that acted as a first and second level referral handling both complicated and uncomplicated cases [23]. The General Hospital housed a Non-Governmental Organization named A Safer Zambia (ASAZA) that facilitated legal and social services for victims of Gender Based Violence. All cases of GBV from Health Centers within Kabwe District were referred to Kabwe General Hospital $(\mathrm{KGH})$ via ASAZA to access services within the one stop center. The Out Patient Department (OPD) was the first point of contact between victims of GBV and Health Professionals. This is where screening and referral of victims to ASAZA / Police Victim Support Unit took place. Victims who needed admission for critical injuries arising from GBV were admitted to female wards. However every entry point for women to a health facility is a potential point to identify victims of spousal physical abuse by alert HPs. Kabwe district was therefore a suitable site for the study as HPs were in contact with women and victims of GBV who were admitted, nursing their children or sought services under the one stop center for GBV related health complaints. The study population included all Doctors, Nurses and Clinical Officers.

Stratified random sampling was applied to select a total of 207 participants, (19 Doctors, 43 Clinical Officers and 145 nurses). To be eligible to participate in the study, the respondents should have worked in Kabwe district public Health facilities for a period of six months and only those health workers who come in contact with women during their work operations including during on call duties. A Selfadministered questionnaire designed and adapted from the International Planned Parenthood Federation/ Western Hemisphere Region's Provider Knowledge, Attitudes and Practices Survey Questionnaire [9], was 
used to collect data. The knowledge questions were adapted to the Zambian National Gender Based Violence Multi - Sectoral training Manual [1]. The advantage of using a self-administered questionnaire was that HPs were able to carry it and filled it in at their own convenient time within the stipulated time frame. The only disadvantage the researcher encountered was that some respondents took long to complete the questionnaire. The researcher had to intensify followups to individual took residential homes before all the questionnaires were returned.

The self-administered questionnaire had a set of pre-determined closed ended questions with the same wording and order of questions. Respondents were allowed to express their views and opinions in the space provided under any other if the available options did not offer their preferred response. The data collection tool consisted of four sections. Section A consisted of questions on socio- demographic data. Questions in this section included age, sex, marital status, profession, highest professional qualifications and duration on current job as well as training on GBV. Section B contained questions that captured Health Professionals' Knowledge on GBV in general. The respondents' knowledge levels on GBV are presented. Respondents were asked a total of 8 statements with response options ranging from true, false and I don't know. The results are presented in table 4. Further, the respondents' knowledge levels on GBV were measured by creating a knowledge score by adding all knowledge questions to come up with a knowledge total score of 8 . Each correct response was awarded a score of 1 while a wrong response and "I don't know responses" were not awarded any score. HPs who obtained scores of 5-8 of the total score were categorized as having high levels of knowledge while those who scored less than 5 (1-4) were considered as having low levels of knowledge. Section $\mathrm{C}$ had questions on screening practices of health professional. The screening practices were measured by a "yes" and "no" question, type of screening and frequency of screening. Scores were allocated to each of the mentioned variable to come up with a practice score of 6 . Furthermore those who obtained scores of 5 - 6 out of the total screening score were considered as adequate screening while scores of less than 5 were considered as inadequate screening practices.

Section D had questions designed to evaluate HPs reporting practices for GBV to legal authorities.
The HPs' reporting practices of GBV were measured by a "yes" and "no" response to a question that sought to find out whether HPs screened for GBV, the type of reporting and frequency of reporting in the past year. Scores were allocated to each of the mentioned measurement criteria to come up with a total reporting score of 6 . Furthermore scores of 4 and above out of the total reporting score were considered as sufficient reporting while scores of less than 4 were considered as insufficient reporting practices. Data was collected from the health professionals using a pretested selfadministered questionnaire. The response rate was $100 \%$. It was checked for consistency and entered into SPSS version 22. Chi-square test was used to determine the association between the independent (Demographic variables, knowledge levels) and dependent variables (Screening and reporting). The statistical significance was set at $5 \%(0.05)$ and confidence interval was set at $95 \%$.

\section{Ethical Consideration}

Ethical clearance was obtained from the Excellence in Research Ethics and Science (ERES) Converge. Written permission was obtained from the Provincial Permanent Secretary, Provincial Medical and Nursing Officers, District Health Office and from the Medical Superintendent of Kabwe General Hospital. An informed consent form prepared according to the Excellence in Research Ethics and Science (ERES) Converge IRB guidelines was issued to the participants in order to guarantee voluntary participation and confidentiality. The researcher gave the address of the Excellence in Research Ethics and Science (ERES) Converge and her contact phone numbers to participants of the questionnaire in case they wanted further clarity on the study. The purpose of the study was explained to each respondent. Those that did not consent to participate in the study were reassured that they would suffer no consequences as a result of not participating. Those who consent were asked to sign a consent form, which was explained fully to them and that they would not be remunerated in any way. Study subjects were told that they were free to withdraw from the study at any time without suffering any consequence. Respondents' names were not written on the questionnaires. No one apart from the researcher was allowed unnecessary access to the collected data. Participants were not subjected to any physical harm as the study. 


\section{RESULTS}

\section{Respondent's socio-demographic data}

Table-1: Respondents socio-demographic data $(n=207)$

\begin{tabular}{|c|c|c|}
\hline Characteristic & Frequency & Percent \\
\hline \multicolumn{3}{|l|}{ Age } \\
\hline$\leq 26$ years & 46 & 23.6 \\
\hline $27-37$ years & 86 & 44.1 \\
\hline $38-48$ years & 45 & 23.1 \\
\hline$\geq 49$ years & 18 & 9.2 \\
\hline Total & 195 & $100 \%$ \\
\hline \multicolumn{3}{|l|}{ Gender } \\
\hline Male & 65 & 31.4 \\
\hline Female & 142 & 68.6 \\
\hline Total & 207 & $100 \%$ \\
\hline \multicolumn{3}{|l|}{ Marital status } \\
\hline Single & 68 & 32.9 \\
\hline Married & 121 & 58.5 \\
\hline Divorced & 2 & 1 \\
\hline Widowed & 16 & 5.6 \\
\hline Total & 207 & $100 \%$ \\
\hline \multicolumn{3}{|c|}{ Health care practitioner } \\
\hline Nurse/midwife & 145 & 70 \\
\hline Clinical officer & 43 & 20.8 \\
\hline Medical Doctor & 19 & 9.2 \\
\hline Total & 207 & $100 \%$ \\
\hline \multicolumn{3}{|c|}{ Highest professional qualification } \\
\hline Degree & 31 & 15 \\
\hline Advance Diploma & 10 & 4.8 \\
\hline Diploma & 100 & 48.3 \\
\hline College certificate & 66 & 31.9 \\
\hline Total & 207 & $100 \%$ \\
\hline \multicolumn{3}{|c|}{ Duration of working in the current Job } \\
\hline$<5$ years & 69 & 35.0 \\
\hline $5-10$ years & 58 & 29.5 \\
\hline$>10$ years & 70 & 35.5 \\
\hline Total & 197 & $100 \%$ \\
\hline \multicolumn{3}{|c|}{ Received training or sensitization on management of GBV } \\
\hline Yes & 39 & 18.8 \\
\hline No & 168 & 81.2 \\
\hline Total & 207 & $100 \%$ \\
\hline
\end{tabular}

Table 1 shows that majority $(44.1 \%)$ of the respondents were aged between 27 to 37 years. Most $(68.6 \%)$ of them were females and $58.5 \%$ were married. Most respondents, $70 \%$ were Nurse/Midwives with a
Diploma qualification $(48.3 \%)$. The majority $(70 \%)$ of the respondents had worked for more than 10 years in their current job and $(81.2 \%)$ had not received training or sensitization on management of GBV. 
Table-2: Knowledge of Health Professionals on GBV (n=207)

\begin{tabular}{|c|c|c|}
\hline Variable & Category & Frequency/ percent \\
\hline \multirow{2}{*}{$\begin{array}{l}\text { A woman is more likely to be assaulted on the street by unknown } \\
\text { men than in her own home by her husband }\end{array}$} & Correct & $144(69.6)$ \\
\hline & Not Correct & $63(30.4)$ \\
\hline \multirow{2}{*}{$\begin{array}{l}\text { GBV is very rare among women seeking health services at health } \\
\text { institutions }\end{array}$} & Correct & $117(56.5)$ \\
\hline & Not Correct & $90(43.5)$ \\
\hline \multirow{2}{*}{$\begin{array}{l}\text { Domestic violence affects all sectors of society irrespective of } \\
\text { social, economic, cultural and religious values }\end{array}$} & Correct & $187(90.3)$ \\
\hline & Not Correct & $20(9.7)$ \\
\hline \multirow{2}{*}{$\begin{array}{l}\text { Most women victims of GBV would not disclose GBV as the } \\
\text { source of their injuries to Health Care Providers }\end{array}$} & Correct & $184(88.9)$ \\
\hline & Not Correct & $23(11.1)$ \\
\hline \multirow{2}{*}{$\begin{array}{l}\text { It is mandatory for Health professionals to report identified cases of } \\
\text { GBV to police }\end{array}$} & Correct & $93(44.9)$ \\
\hline & Not Correct & $114(55.1)$ \\
\hline \multirow{2}{*}{$\begin{array}{l}\text { Victims of GBV are required to obtain a police medical report form } \\
\text { (medico-legal examination report form) from the police or ASAZA } \\
\text { before provision of medical services (except in emergencies). }\end{array}$} & Correct & $31(15.0)$ \\
\hline & Not Correct & $176(85.0)$ \\
\hline \multirow{2}{*}{$\begin{array}{l}\text { It is the role and responsibility of Health professionals to enquire } \\
\text { about gender based violence where the victim tries to conceal it }\end{array}$} & Correct & $162(78.3)$ \\
\hline & Not Correct & $45(21.7)$ \\
\hline \multirow{2}{*}{$\begin{array}{l}\text { Clinical care for survivors of GBV require Health care } \\
\text { Professionals to obtain an informed consent from victims for any } \\
\text { notifications or referral }\end{array}$} & Correct & $166(80.2)$ \\
\hline & Not Correct & $41(19.8)$ \\
\hline
\end{tabular}

Table 2 shows that majority of the respondents (88.9\%) knew that most women victims of GBV would not disclose GBV as the source of their injuries to Health Care Providers. Close to half, (43.5\%) of the respondents endorsed to a false statement that GBV is very rare among women seeking health services at health institutions as true. More than half $(55.1 \%)$ of the health professionals did not know whether it was mandatory for Health professionals to report identified cases of GBV to police. Further, the majority (85\%) of the respondents endorsed to a false statement that victims of GBV were required to obtain a police medical report form from the police or ASAZA before provision of medical services. The Majority of the HPs, (78.3\%) knew that it is the role and responsibility of Health professionals to enquire about gender based violence where the victim tries to conceal it. However, most $(80.2 \%)$ of the HPs knew that Clinical care for survivors of GBV required them to obtain an informed consent from victims for any notifications or referral. The results show that $(79.7 \%)$ of the respondents' in the current study had high knowledge level of GBV while (20.3\%) had low knowledge levels on GBV.

Table-3: Screening for GBV by HPs $(n=207)$

\begin{tabular}{|l|l|l|}
\hline Screened clients & Frequency & Percent \\
\hline Yes & 112 & 54 \\
\hline No & 95 & 46 \\
\hline Total & $\mathbf{2 0 7}$ & $\mathbf{1 0 0}$ \\
\hline \multicolumn{3}{|l|}{ Type of Screening (n= 112) } \\
\hline Part of routine history & 16 & 14.3 \\
\hline Upon suspicion for GBV & 81 & 72.3 \\
\hline Self-disclosure & 13 & 11.6 \\
\hline Other & 2 & 1.8 \\
\hline Total & $\mathbf{1 1 2}$ & $\mathbf{1 0 0 \%}$ \\
\hline \multicolumn{3}{|l|}{} \\
Frequency of GBV screening $(\mathbf{n}=\mathbf{1 1 2})$ \\
\hline Never & 10 & 8.9 \\
\hline Rarely & 28 & 25 \\
\hline A few times & 45 & 40.2 \\
\hline Often & 19 & 17.5 \\
\hline Very often & 10 & 8.9 \\
\hline Total & $\mathbf{1 1 2}$ & $\mathbf{1 0 0 \%}$ \\
\hline
\end{tabular}

Table3 indicates that slightly more than half (54\%) of the health professionals screened women for GBV. The majority, $(72.3 \%)$ of the HPs screened upon suspicion for GBV while (14.3\%) screened as part of routine history taking. The frequency of GBV screening was often, $(17.5 \%)$ and very often, $(8.9 \%)$. About $(83.6 \%)$ of the respondents in the current study exhibited inadequate screening practices for GBV. A 
statistically significant relationship was observed practices for GBV $(\mathrm{p}-0.020)$.

between respondents' profession and their screening

Table-4: Reporting of GBV by HPs $(n=207)$

\begin{tabular}{|l|l|l|}
\hline Re ported GBV & Frequency & Percent \\
\hline Yes & 65 & 31.4 \\
\hline No & 142 & 68.6 \\
\hline Total & $\mathbf{2 0 7}$ & $\mathbf{1 0 0}$ \\
\hline \multicolumn{2}{|l|}{} \\
\hline Mype of reporting $(\mathbf{n}=\mathbf{6 5})$ & 22 & 33.8 \\
\hline Voluntary & 36 & 55.4 \\
\hline If victim has severe injuries & 3 & 4.6 \\
\hline Other & 4 & 6.2 \\
\hline Total & $\mathbf{6 5}$ & $\mathbf{1 0 0 \%}$ \\
\hline \multicolumn{3}{|l}{} \\
Frequency of GBV reporting (n= 65) \\
\hline Never & 8 & 12.5 \\
\hline Rarely & 23 & 35.4 \\
\hline A few times & 22 & 33.8 \\
\hline Often & 8 & 12.3 \\
\hline Very often & 4 & 1.4 \\
\hline Total & $\mathbf{6 5}$ & $\mathbf{1 0 0 \%}$ \\
\hline
\end{tabular}

According to table 4, close to one third, $31.4 \%$ of the HPs reported GBV to legal authorities. Types of reporting were voluntary, $55.4 \%$ and mandatory, $33.8 \%$. The HPs' frequency of reporting GBV was often, $12.3 \%$ and very often $1.4 \%$. Eighty seven percent
$(87 \%)$ of the HPs exhibited insufficient reporting practices of GBV. A statistically significant was between respondents' training and their reporting practices for GBV ( $\mathrm{p}$ - 0.039).

Table-5: Availability of written policy / protocol on screening and reporting of GBV (n=207)

\begin{tabular}{|l|l|l|}
\hline Variable & Frequency & Percent \\
\hline Written institutional policy on screening GBV available & 31.4 \\
\hline Yes & 65 & 38.2 \\
\hline No & 79 & 30.4 \\
\hline I don't know & 63 & $\mathbf{1 0 0}$ \\
\hline Total & $\mathbf{2 0 7}$ \\
\hline Policy statement on GBV screening ( $\mathrm{n}=65)$ & 33.8 \\
\hline Part of routine history taking & 22 & 41.5 \\
\hline upon suspicion for GBV & 27 & 24.6 \\
\hline upon self-disclosure & 16 & $\mathbf{1 0 0 \%}$ \\
\hline Total & $\mathbf{6 5}$ & 29.5 \\
\hline Written Reporting policy for reporting GBV available & \multicolumn{2}{|l|}{} \\
\hline Yes & 61 & 37.7 \\
\hline No & 74 \\
\hline I don't know & 72 & $\mathbf{1 0 0 \%}$ \\
\hline Total & $\mathbf{2 0 7}$ \\
\hline Policy statement on GBV reporting (n=61) & 18.0 \\
\hline $\begin{array}{l}\text { Health professionals should fill in a police (medico - legal examination) report } \\
\text { form even if the victim does not want or has not given consent }\end{array}$ & 11 \\
\hline $\begin{array}{l}\text { Health professionals should only fill in a police (medico - legal examination) } \\
\text { reporting form if the victim has consented and wants to report }\end{array}$ & 46 \\
\hline Other & \multicolumn{2}{|l|}{} \\
\hline Total & $\mathbf{6 1}$ & $\mathbf{7 5 . 4}$ \\
\hline
\end{tabular}

Table 5 shows that the majority of the respondents, $38.2 \%$ indicated that they did not have written institutional policy / protocol on how to screen for GBV while close to one third, $30.4 \%$ of the health professionals did not know whether their institutions had one. When asked if they had a written policy/ protocol on how to report GBV to legal authorities, the 
Table-6: Levels of Confidence on screening and reporting GBV cases $(\mathbf{n}=\mathbf{2 0 7})$

\begin{tabular}{|l|c|l|}
\hline \multicolumn{1}{|l|}{ Variable } & Frequency & Percentage \\
\hline Confidence on screening GBV & \\
\hline Not at all confident & 28 & 13.5 \\
\hline Slightly confident & 52 & 25.1 \\
\hline Moderately confident & 69 & 33.3 \\
\hline Very confident & 47 & 22.7 \\
\hline Extremely confident & 11 & 5.3 \\
\hline Total & $\mathbf{2 0 7}$ \\
\hline Confidence on reporting GBV & $\mathbf{1 0 0}$ \\
\hline Not at all confident & 37 & 17.9 \\
\hline Slightly confident & 50 & 24.2 \\
\hline Moderately confident & 55 & 26.6 \\
\hline Very confident & 50 & 24.2 \\
\hline Extremely confident & 15 & 7.2 \\
\hline Total & $\mathbf{2 0 7}$ \\
\hline
\end{tabular}

According to table 6, few of the HPs were very confident, $22.7 \%$ or extremely confident, $5.3 \%$ that they could screen women for GBV. Further, very few, 24.2\% of the participants reported that they were very confident, $24.2 \%$ or extremely confident, $7.2 \%$ that they could report GBV to legal authorities.

\section{DISCUSSION}

The study sample was drawn from Health Professionals working in public Health facilities in Kabwe District. The findings revealed that there were more females $(68.6 \%)$ than male Health Professionals $(31.4 \%)$ and majority were married, $58.5 \%, 70.0 \%$ were Nurses/midwives (Table 1). The explanation for having more females is that most health professionals are Nurses Midwives and Nursing is a female dominated job. This is because Nursing and Midwifery were previously regarded as female careers. Furthermore, culture ascribes the role of caring for the sick to females and hence more females were joining the Nursing profession. The finding that the majority of the HPs in the study were nurses implies that nurses are the ones found at most of the health facilities and can be instrumental in screening women for GBV. The HPs' mean duration of working on the current job was $9.6 \pm 8.6$ years and on average, they were above 30 years old. The age and sex of a Health Provider might be cardinal feature if women victims of physical abuse are to feel comfortable and gain trust of the HP to discuss their experiences of abuse. It has been reported that women prefer to be screened by a fellow woman HP aged between 30 and 50 years [21]. This entails that it is critical that nurses being the majority among the other Health Professionals should be equipped with knowledge on GBV through ongoing training and sensitization on GBV management. In the absence of a clinical officer or a doctor, Nurses screen and make critical decisions over patients' management. Nurses who are not knowledgeable or trained may not suspect abuse and would not know how to respond to a disclosure of GBV.

The study findings indicate that most of the professionals, $81.2 \%$, did not receive any training / sensitization on GBV (Table 1). This is because issues of GBV were not in the HPs' curriculum as they were culturally considered as private family issues. These findings are similar to a study conducted by Ariel [40] in Barbados which found that $81 \%$ of the Service providers surveyed had no training related to GBV in the last three years. This meant that the service providers were not updated on any policy changes on GBV management that could have enacted in the past three years. However, the finding is contrary to results from a 2015 exploratory study of Australian Midwives' knowledge of intimate partner violence against women during pregnancy by Baird et al. [24] that revealed that almost $88 \%$ of the participants had some education or training on intimate partner violence. This study was limited to Midwives and possibly pregnant women were considered to be a high risk group for GBV, hence it was seen as necessary to train the Midwives in GBV. Others have also observed that generally HPs do not receive formal pre-service and in-service training or professional development on addressing GBV [25]. This may result into lack of knowledge on GBV issues and negative attitudes towards victims of GBV. It is therefore cardinal for professional bodies to strengthen and include GBV issues in HPs curriculum to enable equip them with knowledge and skills on GBV management.

The study assessed HPs' knowledge levels on GBV and most of the respondents knew that most women victims of GBV would not disclose GBV as the source of their injuries to Health Care Providers (Table 2). This knowledge is critical if HPs are to be convinced 
to screen women for GBV instead of waiting for them to spontaneously disclose abuse without being questioned. Close to half, $43.5 \%$ of the respondents endorsed to a false statement that GBV was very rare among women seeking health services at health institutions as true. This statement underestimates the magnitude of GBV among women seeking health facilities. This could be the explanation of reluctance to screen women for GBV. More than half $(55.1 \%)$ of the health professionals did not know whether it was mandatory for Health professionals to report identified cases of GBV to police. Further, the majority (85\%) of the respondents endorsed to a false statement that victims of GBV were required to obtain a police medical report form from the police or ASAZA before provision of medical services.

Approximately, $78.3 \%$ of the HPs knew that it is the role and responsibility of Health professionals to enquire about gender based violence where the victim tries to conceal it. However, most $(80.2 \%)$ of the HPs knew that Clinical care for survivors of GBV required them to obtain an informed consent from victims for any notifications or referral. Obtaining informed consent is very important as it upholds the victim's autonomy and right to choices. Informed consent is still applicable even where reporting to legal authorities is mandatory. This is achieved by giving advance information so that the victim is made aware of the steps that would be undertaken following a disclosure of abuse. In Zambia, HPs are required to fill in a medical report form which is used to confirm the abuse and also to notify the police or any organization that deals with GBV.

Overall, the majority, $79.9 \%$ of the respondents had high levels of knowledge on gender based violence. This finding was unexpected as most of the professionals, $81.2 \%$ (Table 2) were not trained on GBV as such lower levels of knowledge were expected. However, knowledge can also be acquired through long duration of practicing on the job as well as social media. Some $(35.5 \%)$ of the respondents had been on the job for more than 10 years. This long working experience could also be the source of their knowledge. Knowledge gives confidence and facilitates reporting of GBV. A related cross sectional study by Sanchez [26] involving 167 nurses from Urban Health centers to determine the Knowledge and attitudes of Nurses in Primary care on gender Violence and their relationship with socio-demographic factors and cases detected found medium levels of Knowledge. Study findings by Clark et al. [27] on practices, policies, barriers and opportunities for a coordinated and routinized response to IPV revealed that HPs acknowledged GBV to be a serious health threat and believed that screening for GBV was within their scope of work. Yet over two thirds of the participants reported lack of Knowledge among other identified barriers to screening for intimate partner violence.
Screening women for GBV is a critical step in identification of those victims of GBV who may want to conceal the root cause of their complaints. Health professionals who screen women who seek health care services at health facilities for GBV can help identify victims who suffer in silence and can reduce victimization and positively impact women's health and well-being [27]. The current study revealed that slightly more than half $(54 \%)$ of the HPs screened women for GBV (Table 3). This finding means that screening for GBV was low among the HPs. The majority, $72.3 \%$ of the HPs screened upon suspicion, which is also known as selective screening, followed by routine screening, 14.3\%. Overall the HPs' screening practices were inadequate, $83.6 \%$. The possible explanation for the findings is that the majority of the respondents had not received training sensitization on GBV. Although the majority of the respondents had high levels of knowledge on GBV (Table 3), the source of their information or knowledge on GBV was not known as such they could still be harbouring some negative attitudes towards GBV victims and screening for GBV. The low screening rates could further be attributed to the HPs' low confidence levels on screening for GBV as the study showed that only few of these Health professionals reported that they were very confident, $22.7 \%$ or extremely confident, $5.3 \%$ that they could screen women for gender based violence (Table 6). The other contributing factor could be lack of a policy / guidelines or lack of knowledge if one existed on GBV. Knowledge of policies and the implementation of an appropriate protocol increase the likelihood of screening for GBV [28]. The current study revealed that $38.2 \%$ of the Health professionals reported that they did not have a written policy (procedures and protocols) on screening women for GBV while close to one third $30.4 \%$ of the health care professionals did not know whether their institutions had written policies on screening for GBV table 5. Another Zambian study in Northwestern Province conducted in two study sites also revealed that the study sites did not have written protocols to guide coordination, case management and harmonization of referral pathways and follow-up between the various service providers on providing care and assistance to survivors of GBV [29]. Several studies affirm the importance of having an institutional policy to guide HPs on screening for GBV; A Jamaican study by Pitter [30] that assessed midwives' knowledge and attitudes when encountering GBV in their practice revealed that the midwives acknowledged the importance of screening for GBV and expressed willingness to intervene but identified barriers in form of gaps in the institutional framework to guide their practice.

This notion is further supported by findings from a study by Bender [31] that revealed that knowledge and attitudes did not predict screening, rather the number of hours of previous training on abuse and the organizational protocols of the health 
facility where HPs are employed significantly increased the frequency of Intimate Partner Violence (IPV) screening In conclusion, Bender [31] suggests that external factors such as national policies mandating IPV screening in clinics may be an effective way to increase provider identification of IPV.

Several research studies have also reported low rates of screening for GBV. A Californian survey of 137 primary care physicians' self-reported screening practices by Tavrov et al. [32] revealed that only $14 \%$ of the health providers in their study always screened female patients for IPV, about one third of the health care providers appeared never to screen. The reason for the low screening rates was that most Health care providers in the study lacked self confidence in screening. Another cross sectional study by Suryavanshi et al. [33]. in India on women's' opinions on GBV screening found that among $23 \%$ of women who reported experiences of GBV, $90 \%$ had never been asked about GBV in a health facility. This finding indicates that victims of GBV pass through Health facilities but HPs fail to identify them due to reluctance to screen for GBV.

Low screening rates were also revealed by Ramsey et al. [34] in a study to measure Primary care Clinicians' current levels of knowledge, attitudes and clinical skills on domestic violence. The study found that screening for GBV was not widespread even when patients presented with signs and symptoms of abuse, only about $51 \%$ of clinicians in their study asked such patients about possibility of abuse. It is cardinal for HPs to inquire about GBV in female patients who present with signs of abuse in view of the high prevalence of spousal physical abuse. GIDD [35] encourages Health care Professionals to ask about abuse upon noting inconsistencies in the victim's history and the indicators of abuse.

Although the current study revealed that the majority, $72.3 \%$, of the HPs' screened for GBV upon suspicion, (also known as selective screening), others have recommended routine screening. Dudgeon and Evans [36] state that routine screening does not only create opportunities for women to disclose abuse but also facilitates provision of support and assistance from Heath care providers consequently curbing adverse health effects. Several studies affirm the importance of having an institutional policy to guide HPs on screening for GBV.

A statistically significant relationship was observed between respondents' profession and their screening practices for GBV $(\mathrm{p}=0.020)$. The proportion of adequate screening practices was higher in respondents who were clinical officers $(27.9 \%)$ and medical doctors $(26.3 \%)$ in comparison with those who were Nurses/Midwives (11.7\%). This finding could be attributed to the fact that clinical Officers and doctors are adequately trained to screen patients during their professional training. Clinical Officers work closely with medical doctors and are mostly found in the outpatient department screening patients while Nurses implement the orders among other nursing duties more especially in big facilities such as hospitals where there is division of labour. However due to shortages of Clinical officers and Doctors, the division of labour in terms of screening patients is not strictly adhered to as nurses being the majority are found at various entry points of Health facilities screening and interacting with female clients. Therefore regardless of where they work, nurses need to be equipped with knowledge on GBV to enable them to screen and intervene appropriately to a disclosure of GBV. Women might even be more comfortable to discuss GBV issues with fellow women. On the other hand, most nurses are females, imply that they are not immune to GBV and may have accepted their own experiences of GBV as such may not see any reason to screen other women for GBV.

Reporting GBV to legal authorities in this study refers to filling in a police medical report form or referring a victim of GBV to another level such as ASAZA or the Police victim support unit. Sometimes HPs use a phone call to inform the Police when a victim has sustained severe injuries and require admission (Table 4). The Police officers follow the victim at the Hospital. Nurses and many of the Clinical officers are not authorized to fill in a police medical report form, but they are mandated to refer cases of GBV to another level where there is a medical doctor, usually to Kabwe General Hospital via ASAZA. Medical doctors are the ones who are authorized to fill in a police Medical report form for victims of GBV. It is therefore, cardinal for HPs and the law enforcement agency to coordinate in managing cases of GBV. A one stop center for GBV victims is located within Kabwe General Hospital to ease off the reporting of GBV cases to legal authorities. The current study revealed that close to one third, $31.4 \%$ of the HPs reported GBV to legal authorities, (Table 6). The types of reporting engaged by the majority, $55.4 \%$ of the respondents were voluntary, followed by mandatory, $33.8 \%$ (Table 6). The HPs' frequency of reporting GBV was often, $12.3 \%$ and very often $1.4 \% \%$ (Table 6 ). Overall, the HPs reporting practices for GBV to legal authorities were insufficient, $87 \%$. The reason for the HPs' low reporting rates and insufficient reporting practices could be explained by lack of training on GBV. A higher proportion of respondents who had received training on GBV $(23.1 \%)$ exhibited sufficient reporting practices as compared to those who had not received training, where sufficient reporting stood at $10.7 \%$. The observed relationship was statistically significant ( $\mathrm{p}-0.039)$. We therefore rejected the null hypothesis and concluded that there is a relationship between respondents' training or sensitization on GBV and Health professionals' reporting practices for GBV $(\mathrm{p}<0.005)$. 
The explanation for this finding is that HPs who are trained are aware of the reporting and referral requirements for cases of GBV and they confidently implement the required behavioral action when GBV is disclosed. Victims of GBV are referred to a higher level Hospital where there is a medical doctor via ASAZA to obtain a police medical report form. Doctors are obliged to fill in a medical report form which is given to the victim to return to ASAZA to facilitate opening of a docket. Although, some victims of GBV may not return the form to ASAZA or Police, the HP would have accomplished their role. The finding of low reporting rates for GBV is in line with reports that GBV is under reported and that HPs are reluctant to report GBV to legal authorities even in nations where mandatory reporting laws exist [29]. It is therefore important for health institutions to have a written policy/ protocol to guide HPs on how to screen for GBV.

A Medical personnel or an institution with information concerning the commission of an act of GBV can obtain for the victim or advise the victim on how to obtain shelter, medical services or other services that may be required in the circumstances of GBV [37]. This entails that HPs may obtain police services for the victim among other services required in the multidisciplinary management of GBV. The act under part 6 , sub section 1 and 3 further stipulates that a victim of GBV may file a complaint about gender based violence but also a complaint of GBV may be filed by any other person or institution with information about the gender based violence where the intervention is in the interest of the victim [37]. This statement implies that HPs can report GBV to police authorities and even file a complaint on behalf of the client in circumstances where this is in the interest of the client. Moreira et al. [38] in a Brazilian based study to analyze training and knowledge of professionals who worked in the family Health Strategy on reporting mistreatment of children and adolescents also report that $86.3 \%$ of the professionals were not trained on GBV as such gaps in knowledge were detected which translated into difficulties in reporting the identified abuse. Reporting of abuse was low, $17 \%$. The study also showed that among $37.2 \%$ of the professionals who had identified abuse, $60 \%$ reported the abuse to authorities. The variables identified in the final model showed a direct association between the act of reporting and matters related to knowledge and training about abuse. A US survey by Cooper et al. [39] on knowledge, detection and reporting of abuse by Health Professionals also found that Professionals who had received training on GBV were likely to report the detected abuse than those who were not trained. This finding could be attributed to the fact that training increased Knowledge levels and confidence on GBV reporting.

\section{Strength and limitations of the study}

This study has achieved the main objective of examining the knowledge and practices of Health
Professionals towards screening and reporting GBV among women to legal authorities in Kabwe District. There has been no study focusing on the variables, knowledge, screening/ reporting practices, locally in Zambia. Most of the studies that have been conducted by other researchers on the subject regionally and globally only discuss whether HPs screen women for GBV or report GBV but do not bring out the actual screening and reporting practices engaged by HPs. Apart from categorizing the HPs' responses into high and low levels of knowledge, this study also highlights performance of the study participants on individual knowledge questions. This is helpful in guiding capacity builders as to what issues need to be address and clarified in their training programmes. Victims of GBV are required to obtain a police medical report form from the police or ASAZA but they are entitled to medical services even without a medical form. The medical form could still be obtained afterwards. The requirement for HPs to refer victims of GBV to a higher level health facility via ASAZA for the purpose of obtaining and having a police medical report form filled in and signed by a medical doctor. The need for advance information to the victim during screening including the filling in of a police medical form and its use. This study has several limitations. The study was only conducted in Kabwe District and therefore results cannot be generalized to other Districts in Zambia. There is need to conduct a similar study on a national scale to generalize the findings. The knowledge, screening and reporting practices were self-reported, therefore follow up questions were included as necessary to probe further and allow self- expression. There was no methodological triangulation for data collection, however a category under 'any other' was created where necessary to allow free self- expressive statements to supplement on the data or clarify issues. Doctors and clinical Officers were very few in the study; a larger sample size was desirable however their responses have shed light on the subject. Doctors and Clinical Officers were selected using of convenient sampling which is a non-probability method that is prone to selection bias and the study sample may not be representative of the study population making it difficult to generalize of study finding.

\section{CONCLUSION}

The findings showed that a high percentage of the HPs had not been trained or sensitized GBV. Slightly more than half of the HPs screened women for GBV, mostly upon suspicion for GBV which is also known as selective screening. Regarding the frequency of screening for GBV, few of the HPs' screened often, and very often. The majority of the respondents indicated that they did not have a written institutional policy / protocol on how to screen for GBV while close to one third of the HPs did not know whether their institutions had one. The study also revealed that few of the HPs were very confident or extremely confident that they could screen women for GBV. Overall, the HPs' 
screening practices for GBV were inadequate. A significant relationship was observed between profession and screening. The proportion of adequate screening practices was higher in respondents who were clinical officers and medical doctors in comparison with those who were Nurses/Midwives.

About one third of the HPs report GBV to legal authorities using a variety of reporting types, over half of the HPs use voluntary and slightly above one third use mandatory type of reporting. Very few of the HPs reported GBV to legal authorities often, and very often. Overall, the HPs reporting practices of GBV were insufficient. A statistically significant relationship was observed between respondents' knowledge level on GBV and reporting practices, training and reporting practices for GBV. Most of the respondents indicated that there was none and slightly over one third of the HPs did not know if there was one. Very few of the participants were very confident, or extremely confident that they could report GBV to legal authorities. There is need therefore for Ministry of Health to review and periodically disseminate updated written guidelines / protocols on GBV management on screening and reporting requirements for GBV by HPs to all health institutions to keep HPs abreast on current GBV management practices. The Ministry of Health and the General Nursing and Midwifery Council of Zambia should address the gaps identified in screening women for gender based violence by including in depth information on screening and reporting policies and requirements on GBV in the Nursing curriculum.

\section{ACKNOWLEGEMENT}

The authors would like to thank the participants for their participation and the Ministry of Health for partially sponsoring this study.

\section{REFERENCES}

1. Ministry of Community Development, Mother and Child Health. (2013). National Gender Based violence Multi- Sectoral Training Manual for gender based Violence. Paediatric Centre of Excellency, University Teaching Hospital, Lusaka

2. Ministry of Gender and Child Development. (2014). Zambia's Progress Report on the Implementation of the Beijing Declaration and Platform for Action (1995) and the Outcomes of the twenty-third special session of the General Assembly. (2000). In the context of the Twentieth Anniversary of the Fourth World Conference on Women and the adoption of the Beijing Declaration and Platform for Action 2015 accessed at https://www.uneca.org/sites/default/files/uploadeddocuments/Beijing20/NationalReviews/zambia_bei jing_review_report.pdf on 04/08/2020

3. The World Bank. (2019). Gender based violence (violence against girls and women). Accessed at http://www.worldbank.org/en/topic/socialdevelopm ent/brief/violence-against-women-andgirls

on 21/5/2019

4. UN women. (2013). Thematic evaluation: the contribution of women to prevent Violence against Women and expand access to services. Accessed at http://www.unwomen.org/en/aboutus/ /media/9450 DD6E14244DA082D642AAF734448E.ashx on 21/5/2019

5. Huecker, R., M., \& Smock, W. (2019). Florida Domestic Violence, National Library of Medicine, PMID: 29630246 retrieved from https://pubmed.ncbi.nlm.nih.gov/29630246/ on 14/06/2020.

6. Agisanang Domestic Abuse Prevention and Training (ADAPT). (2019). Oliver Tambo Community Centre. Accessed at http://www.adapt.org.za/ADAPT\%20on\%20GBV. pdf on 04/08/2020

7. European Institute for Gender Equality. (2020). Forms of gender based violence. Accessed at https://eige.europa.eu/gender-based-

violence/forms-of-violence downloaded on 24/05/2020).

8. European Union Agency for Fundamental Rights (FRA). (2016). Thematic focus; Gender based Violence accessed

https://fra.europa.eu/en/theme/asylum-migrationborders/overviews/focus-gender-based-violence on $18 / 03 / 2019$

9. Bott, S. A., Guedes, C. Claramunt., \& Guezmes, A. (2010). Improving the Health Sector Response to Gender-Based Violence: A Resource Manual for Health Care Professionals in Developing Countries: International Planned Parenthood Federation (IPPF) / Western Hemisphere Region (WHR) tools. Accessed at https://www.ippfwhr.org/wpcontent/uploads/2018/ 08/GBV_cdbookletANDmanual_FA_FINAL__1_. pdf on $1 \overline{6} / 5 / 2019$

10. US women's Health. (2018). Domestic or Intimate Partner Violence | womenshealth.gov Us Department of Health and Human Services, office on women's health accessed at https://www.womenshealth.gov/relationships-andsafety/domestic-violence on 29/7/2020

11. Ministry of Gender - Zambia. (2016). Gender Based Violent statistics in Zambia. Accessed at http://www.mgcd.gov.zm/index.php/statistics-andgender-information 6/6/2019

12. ASAZA. (2017 - 2019). Monthly Returns, Kabwe

13. UN Women. (2011). Conduct Screening- Virtual Knowledge center to End Violence. Accessed at http://www.endvawnow.org/en/articles/667conduct-screening.html_on 23/5/2019.

14. Blank, K., \& Rosslhumer, M. (2015). Implement Training Manual - specialized support for victims of violence in healthcare systems across Europe Just/2014/DAP/5361 accessed at http://gbvimplement- 
halth.eu/implement_train_EN_201606_hires.pdf on $23 / 5 / 2019$

15. National Crime research. (2014). Gender Based Violence in Kenya. Accessed at http://crimeresearch.go.ke/wpcontent/uploads/2018/02/wwwroot_publications_G ender-Based-Violence-in-Kenya.pdf on 5/1/2019

16. WHO. (2013). Responding to Intimate Partner Violence and Sexual Violence Against Women: WHO Clinical Policy Guidelines: Evidence and Recommendations. Accessed at http://apps.who.into/iris/bitstream/1066585249/1/9 789241548595_eng.pdf on 21/5/2019

17. Natan, B., Ari, B., Bader, T., \& Hallak, M. (2011). Universal Screening for Domestic Violence in a Department of Obstetrics and Gynecology: A Patient and Career Perspective. International Nursing Review, 2012. 59(1), 108-144 Accessed at https://onlinelibrary.wiley.com/doi/abs/10.1111/j.1 466-7657.2011.00931.x on 20/5/2019.

18. Hewins, E., Dibella, B., \& Maula, J. (2013). Domestic Violence and the Role of the Health Care Provider: The Importance of Teaching, Assessment and Intervention Strategies. Accessed at https://www.verizon.com/about/sites/default/files/ WhitePaper-Domestic-Violence.pdf on 17/5/2017

19. USAID/ ZAMBIA. (2020). Health | Zambia| US agency for International Development Accessed at https://www.usaid.gov/zambia/global-health on 29/07/2020.

20. Ministry of Gender and Child Development and Central statistical office. (2012). Gender status Report- Zambia 2012 - 2014. Accessed at https://www.zamstats.gov.zm/phocadownload/Gen der/Gender\%20Status\%20Report\%2020122014\%20290616.pdf on 29/07/2020

21. Gutamis, I., Beynon, C., Tutty, L., Wathen, C. N., \& Macmillac, H.L. (2007). Factors Influencing Identification of and Response to Intimate Partner Violence: A Survey of Physicians and Nurses. BMC. Public Health 2007 vol. 24, no. 7. Pp. 12 Accessed https://www.ncbi.nlm.nih.gov/pubmed/17250771 accessed on 17/5/2019.

22. Hayden, A. (2010). Why rock the boat? None reporting of intimate partner violence: A thesis submitted to Auckland University of Technology in fulfillment of the requirements for the degree of Doctor of philosophy (PhD). Accessed at https://openrepository.aut.ac.nz/bitstream/handle/1 0292/1301/HaydenA.pdf? sequence $=3$ \&isAllowed $=$ y on $17 / 5 / 2019$

23. Action plan. (2016). District Health Office, Kabwe

24. Baird, K., M., Saito, A., S., Eustace, J., Creedy, D., K. (2015). An exploration of Australian Midwives' knowledge of intimate partner violence against women during pregnancy. Women and birth: Journal of the Australian college of Midwives, 28(3), $215 \quad-\quad 20 \quad$ accessed at https://www.ncbi.nlm.nih.gov/pubmed/25684254 on $29 / 11 / 2018$

25. WHO. (2012). Gender Based Violence in Pakistan; Response in the Perspective of Health Sector Devolution. Accessed at http://application.emro.who.int/dsaf/EMRPUB202_ EN_858 On 22/11/2016

26. Sanchez. V. C. A., Fernandez. G.C., Diaz. S.A. (2016). Gender Violence: Knowledge and attitudes of Nurses in Primary Care. Attencion primaria, 48(10), $623-631 . \quad$ Accessed at http://www.ncbi.nlm.nih.gov/pubmed?cmd=Retrie ve $\& \mathrm{db}=$ Pubmed\&list_uids $=26994656 \quad$ on 21/5/2019

27. Clark, C., J., Renner L., M., \& Logeais, M. (2017). Intimate Partner Violence Screening and Referral Practices in an Outpatient Care setting. Journal of interpersonal violence, 2017, 1: 88626051772453. Accessed https://www.ncbi.nlm.nih.gov/pubmed?cmd=Retrie ve $\& d b=$ PubMed\&list_uids $=29294868 \quad$ on $11 / 11 / 2018$

28. Rodriguez-Blanes. G. M., Vives-Cases. C., Miralles-Bueno J. J., San Sebastian. M., Goicolea. I. (2017). Detection of intimate partner violence in primary care and related factors. Gaceta sanitaria, 31(5) Accessed at http://www.ncbi.nlm.nih.gov/pubmed?cmd=Retrie ve $\& \mathrm{db}=$ PubMed\&list_uids $=28188013 \quad$ on $19 / 11 / 2018$

29. Avocats, S. F. (2017). Challenges of Implementing of the Anti-Gender- Based violence Act by examining the level of its operationalization in two districts. Accessed at https://asf.be/wpcontent/uploads/2017/09/ASF_ZA M_StudyAntiGBVAct_201708_EN.pdf on 9/11/2018

30. Pitter, C. P. (2016). Midwives' knowledge and attitudes when encountering Gender Based Violence in their practice at a maternity hospital in Kingston, Jamaica. International journal of qualitative studies on health and well-being, 11 no. 29358. Accessed at https://wwww.ncbi.nlmnih.gov/pubmed?cmd=Retri eve $\& \mathrm{db}=$ pubmed\&list_uids $=268947444 \quad$ on $9 / 11 / 2018$

31. Bender, A., K. (2016). Using the consolidated framework for implementation research to Increase Provider screening for Intimate Partner Violence in Rural Health Clinics. Womens' Health Issues, 26(4), $\quad 384 \quad-\quad 92 . \quad$ Accessed https://www.ncbi.nlm.nih.gov/pubmed?cmd=Retrie ve $\& \mathrm{db}=$ PubMed\&list_uids $=27365285$ at on $16 / 5 / 2019$

32. Tavrow, P., Bloom, B.E., withers, M.H. (2017). Intimate Partner Violence Screening Practices in California after Passage of the Affordable Care Act. Violence against women, 23(7)871-886 accessed 
https://www.ncbi.nlm.nih.gov/pubmed?cmd=Retrie ve \&db=PubMed\&list_uids $=27312117$ on 5/12/18

33. Suryavanshi, N., Naik. S., Waghmare, S., Gupte, N., Khan, S., Mave, V., Deluca, A., Gupta, A., Golub, J., Bollinger, C.R., \& Shankar, A. (2018). Gender based violence screening methods preferred by women visiting a public hospital in Pune, India. BMC women's health 2018 vol.18 no. 19 Accessed on

https://www.ncbi.nlm.nih.gov/pmc/articles/PMC57 69341 on $21 / 5 / 2019$

34. Ramsay. J., Rutterford. C., Gregory. A. Dunne. D., Eldridge. S., Sharp. D., Feder. G. (2012). Domestic Violence: Knowledge, attitudes and clinical practice of selected UK primary healthcare clinicians. The British journal of general practice: the journal of the Royal College of General Practitioners 2012, vol.62, No. 602.pp. e642 -55. Accessed at https://www.ncbi.nlm.nih.gov//pubmed?cmd=Retri eve $\& \mathrm{db}=$ Pubmed\&list_uids $=22947586 \quad$ on $4 / 12 / 2018$

35. Gender in Development Division (GIDD). (2011). The National Guidelines for the Multidisciplinary Management of Survivors of Gender Based Violence in Zambia, cabinet office.

36. Dungeon. A., \& Evans, T., A. (2014). Intimate partner violence in rural US areas: what every nurse should know. American Journal of nursing, 11(5), 26-35 Accessed at http://www.ncbi.nlm.nih.gov/pubmed?cmd=Retrie ve $\& d b=$ PubMed\&list_uids $=24727408$ on $20 / 11 / 2018$
37. Government of Zambia. (2011). ACT NO. 1 of 2011- Anti Gender Based Violence, Government Printers, Lusaka

38. Moreira. G., A., Vieira. L., G., Deslandes. S., F., Pordeus. M.A., Gama. I.S., Brilhante. A., V. (2014). Factors associated with the report and adolescent abuse in primary healthcare. Cien saude colet, 19(10), 4267-4276. Accessed at https://pubmed.ncbi.nlm.nih.gov/25684254/ on 20/05/2019

39. Cooper, C., Selwood, A., Livingston, G. (2009). Knowledge, detection, and reporting of abuse by health and social care professionals: a systematic review. American Journal of Geriatric Psychiatry, 17(10), 826 - $38 . \quad$ Accessed at https://www.ncbi.nlm.nih.gov/pubmed/19916205 on $17 / 5 / 2019$

40. Ariel, R. K. (2015). Service Providers' Knowledge, Attitudes and Practices on Gender Based Violence and Human Immunodeficiency Virus (HIV) and Acquired Immune Deficiency Syndrome (AIDS). Accessed http://www.arielfoundation.org/images/kingHIVAI DSDecember2015.pdf on 21/5/2019

41. Thackeray, J., Stelznar, S., Downs M. S., Miller, C. (2007). Screening for Intimate Partner Violence: The Impact of Screener and Screening Environment on Victim Comfort, Journal of interpersonal violence, 20(6), 659-70 Accessed at https://pubmed.ncbi.nlm.nih.gov/17515428/ on $29 / 07 / 2020$

\section{APPENDIX 1: PARTICIPANTS' INFORMATION SHEET}

\section{Knowledge, Screening and Reporting Practices of Health Professionals towards Gender Based Violence among Women in Kabwe District}

\section{INTRODUCTION}

My name is Jennipher Akebu N..Soko; a student of Masters of Science in Nursing at the University of Zambia who is kindly requesting for your participation in the research study mentioned. This study is important as it will identify Health Professionals' levels of Knowledge and practices towards Gender Based Violence in women

\section{Purpose of the study}

The study will identify the levels of Knowledge screening and reporting Practices of Health Professionals towards Gender Based Violence in Kabwe District. The information obtained will help the policy makers and implementers of the programme in the Ministry of Health to re-direct programme implementation in order to strengthen the fight against Gender based violence and improve the management of gender based victims in Zambia.

\section{Participation}

Participation in this study is voluntary. If you are not interested in participating in this study you are free to do so. Even after you have joined the study you are free to withdraw as you wish, and this will not affect your working relationship at this center.

If you are willing to participate, you will be asked to sign a consent and agreement to participate, will not result in any immediate benefits. Please ask where you do not understand.

\section{Procedure}

The study involves a set of questions using a structured questionnaire. After signing the consent form, you will be given a self-administered questionnaire to fill in at your convenient time within a period of 2 weeks. 


\section{Risks and discomforts}

There is no risk involved in this research though part of your time will be utilized to answer some questions. Some questions may seem to be sensitive and personal. If you will need further discussion, it will be offered to help you understand the topic more.

\section{Benefits}

There is no direct benefit to you by participating in this study, but the information which will be obtained will help the policy makers to take measures that will ensure that Gender Based Violence is given priority as one of the major public health problems in Zambia. Health Professionals shall receive the necessary training on gender based violence through ongoing capacity building, provision of manuals and management protocols, improved and strengthened networking system. No monetary favors will be given in exchange for information obtained.

\section{Confidentiality}

Your research records and any information you will give will be confidential to the extent permitted by law. You will be identified by a number, and personal information will not be released without your written permission except when required by law. The Ministry of Health, the ERES Converge IRB or the School of Nursing Sciences may review your records again but this will be done with confidentiality

\section{Appendix ii: consent form}

The purpose of this study has been explained to me and I understand the purpose, the benefits, risks and discomforts and confidentiality of the study. I further understand that: If I agree to take part in this study, I can withdraw at any time without having to give an explanation and that taking part in this study is purely voluntary.

I

Agree to take part in this study.

(Names)

Signed/thumb:

\section{(Participant)}

Date:

Signed/thumb:

Date:

\section{(Witness)}

Signed/thumb:

\section{(Researcher)}

Date:

\section{Persons to contact for problems or questions}

The Head of Department,

University of Zambia,

Department of Nursing Sciences,

P.O. Box 50110,

\section{Lusaka.}

Telephone Number 0211252453.

The Chairperson,

ERES CONVERGE

33 Joseph Mwilwa Road,

Rhodes Park,

Lusaka

E-mail: eresconverge@yahoo.co.uk

Tel: +260955155633

+260955155634

+260966765 503

Cell: +260966765 503 


\section{SELF ADMINISTERED QUESTIONNAIRE FOR HEALTH CARE PROVIDERS THE UNIVERSITY OF ZAMBIA DEPARTMENT OF NURSING SCIENCES}

\section{KNOWLEDGE, SCREENING AND REPORTING PRACTICES OF HEALTH PROFESSIONALS TOWARDS GENDER BASED VIOLENCE IN WOMEN IN KABWE DISTRICT}

Date of interview (DD/MM/YYYY): $\mid$

Clinic/health center Name: Code

\section{INSTRUCTIONS FOR THE RESPONDENT}

- Do not write your name on the questionnaire.

- Answer all the questions in the order they are arranged.

- For questions provided with alternatives, tick in the box provided against the most appropriate response(s).

- For questions without alternatives, write down your responses in the spaces provided.

- Be assured that all the information will be treated strictly confidential and only be used for the intended purpose.

- In this survey, Gender Based Violence means physical abuse by an intimate partner.

\section{SECTION A: DEMOGRAPHIC PROFILE}

1. What was your age on your last birthday?

2. What is your sex?
a. Male
b. Female

3. What is your highest professional qualification?
a. Degree
b. Advanced Diploma
c. Diploma
d. College Certificate

4. What is your profession?
a. Nurse/Midwife
b. Medical Doctor
c. Clinical Officer

5. What is your marital status?
a. Single
b. Married
c. Divorced
d. Widowed

6. How long have you been working on your current job? 


\section{Question 7}

Below is a list of statements about gender based violence, screening and reporting. Indicate whether these statements are true or false, by ticking under yes or no respectively or I don't know if you don't know the answer.

\begin{tabular}{|c|c|c|c|c|}
\hline 7 & & Yes & No & $\begin{array}{l}\text { I don't } \\
\text { know }\end{array}$ \\
\hline $\mathrm{A}$ & $\begin{array}{l}\text { A woman is more likely to be assaulted on the street by unknown men } \\
\text { than in her own home by her husband }\end{array}$ & & & \\
\hline $\mathrm{B}$ & $\begin{array}{l}\text { GBV is very rare among women seeking health services at health } \\
\text { institutions }\end{array}$ & & & \\
\hline $\mathrm{C}$ & $\begin{array}{l}\text { Domestic violence affects all sectors of society irrespective of social, } \\
\text { economic, cultural and religious values }\end{array}$ & & & \\
\hline $\mathrm{D}$ & $\begin{array}{l}\text { Most women victims of GBV would not disclose GBV as the source of } \\
\text { their injuries to Health Care Providers }\end{array}$ & & & \\
\hline$E$ & $\begin{array}{l}\text { It is mandatory for Health professionals to report identified cases of } \\
\text { GBV to police even if the victim has not agreed or consented to } \\
\text { reporting }\end{array}$ & & & \\
\hline $\mathrm{F}$ & $\begin{array}{l}\text { Victims of GBV are required to obtain a police medical report form } \\
\text { (medico-legal examination report form) from the police or ASAZA } \\
\text { before provision of medical services (except in emergencies). }\end{array}$ & & & \\
\hline $\bar{G}$ & $\begin{array}{l}\text { It is the role and responsibility of Health professionals to enquire } \\
\text { about gender based violence where the victim tries to conceal it }\end{array}$ & & & \\
\hline $\mathrm{H}$ & $\begin{array}{l}\text { Clinical care for survivors of GBV require Health care Professionals to } \\
\text { obtain an informed consent from victims for any notifications or } \\
\text { referral }\end{array}$ & & & \\
\hline
\end{tabular}

\section{SECTION C: HEALTH PROFESSIONALS SCREENING PRACTICES}

8. In your practice do you ever screen women for GBV?

a. Yes

b. No F 'No', skip to Question 11

9. Below is a list of statements on screening options for GBV. Indicate which statement best describes your practice by ticking one option from the screening options below (choose 1 option only) I screen (ask about GBV) under the following circumstances:

a. As part of routine history taking for all women who seek medical services

b. Upon suspicion of GBV e.g. if the woman consults for injuries that are not well explained

c. Upon self-disclosure, if the woman voluntarily brings up the topic

d. Any other (explain)

10. In the past year how frequent did you perform the screening option chosen in question number 9 above?

a. Never
b. Rarely
c. A few times
d. Often
e. Very often

\section{SECTION C: HEALTH PROFESSIONALS REPORTING PRACTICES OF GBV TO LEGAL AUTHORITIES}

(NB: reporting can be through a referral, phone call or through a written police medical report form).

1. In your practice do you ever report GBV to legal authorities (Police or ASAZA)?
a. Yes
b. No
IF 'No', go to Question 14 
12. Below is a list of statements on options for reporting GBV to Police or ASAZA. Indicate the statement that best describes your practice by ticking against the option (choose 1 option only)

a. I report GBV to Police/ASAZA even if the victim does not want or consent to reporting

b. I only report GBV if the victim has consented and wants to do so

c. I only report if the injuries are severe and victim is at risk

d. Any other (specify)

13. In the past year how frequent did you carry out the reporting option chosen in question number 12 above?
a. Never
b. arely
c. A few times
d. Often
e. Very often

14. Does your institution have a written policy (procedures and protocols) on screening women for GBV?
a. Yes
b. No
IF 'No' skip to Question 16
c. I don't know
IF 'you don't know' skip to Question 16

15. What does the policy state about screening women for Gender Based Violence? (Choose 1 option only)
a. creening for GBV should be done as part of routine history taking for all women who seek medical care
b. Screening for GBV should be done on suspicion for GBV
c. Screening for GBV should be done upon self-disclosure, if the woman voluntarily brings up the topic
d. Any other (specify)

16. Does your institution have a written policy (procedures and protocol) on how to report Gender Based Violence to Police or ASAZA?
a. Yes
b. No
IF 'No' skip to Question 18
c. I don't know
IF 'you don't know', skip to Question 18

17. What does the policy state regarding reporting Gender based violence to police or ASAZA (Choose 1 option only)

a. Health professionals should fill in a police (medico - legal examination) reporting form even if the victim does not want or has not given consent.

b. Health professionals should only fill in a police (medico - legal examination) reporting form if the victim has consented and wants to report

c. Any other (specify

18. How confident are you that you can screen women for gender based violence?
a. Not at all confident
b. Slightly confident
c. Moderately confident
d. Very confident
e. Extremely confident

19. How confident are you that you can report gender based violence to Police or ASAZA?
a. Not at all confident
b. Slightly confident
c. Moderately confident
d. Very confident 
e. Extremely confident

20. Do you have any comments on Knowledge, screening and reporting practices of Health Professionals towards GBV in women?

Thank you for participating, you have come to the end.

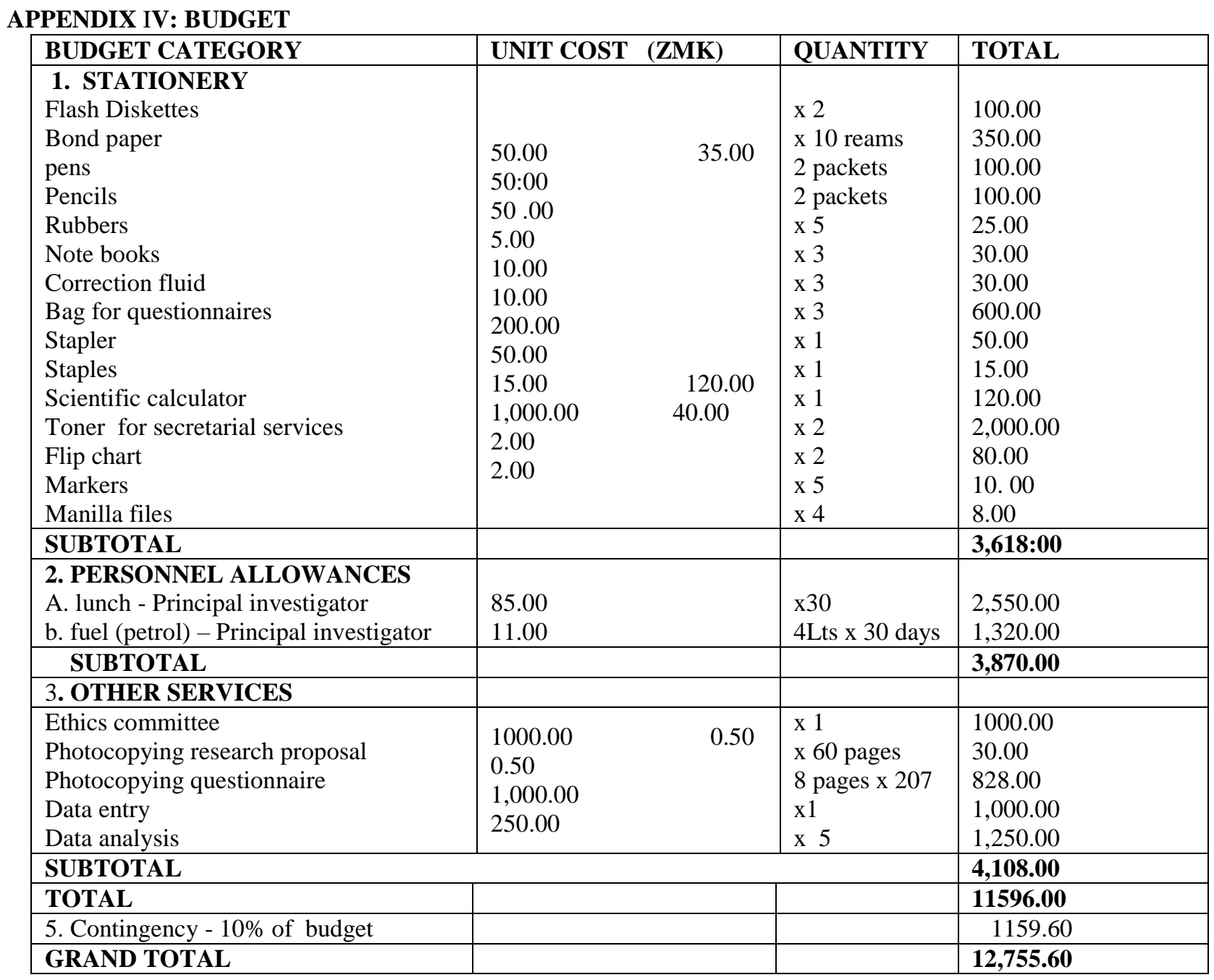

\section{Budget justification}

\section{Stationery}

The 10 reams of bond paper were used for the research proposal development and the final report. Paper was required to make extra copies of the proposal for submission to the ERES Converge IRB and the board of graduate studies. In addition the questionnaire consisted of 8 pages which needed to be photocopied. The flash disc was for copying, storage and safe keeping of research data, soft copies of the research proposal and report. The scientific calculator is needed for making calculations so that accurate data is presented. Other accessories such as pens, pencils, rubbers and note books were required for taking notes throughout the research project. Stapler and staples were required for keeping papers properly arranged all the time. The bag was needed for carrying questionnaires during data collection and for the researcher to ensure that the questionnaires were kept safe.

Personnel emoluments

Collection of questionnaires was conducted throughout the day as such the researcher needed funds for buying food. The research was allocated 30 days to allow adequate time for administration and collection of questionnaires. 


\section{Services}

Funds were required for photocopying and binding of the proposal and report. One copy will be printed and the rest photocopied to cut down on the cost. The research ethics handling fee is required for by research ethics committee which approves the study
Transport

Fuel was needed to take researcher to the data collection sites

Contigency

Contingency fund which was $10 \%$ of the budget was required for any extra costs due to inflation and for any eventualities.

Appendix v: marking key for knowledge questions

\begin{tabular}{|l|l|l|l|}
\hline Q7 & Variable & $\begin{array}{l}\text { Correct } \\
\text { response }\end{array}$ & Score \\
\hline a & $\begin{array}{l}\text { A woman is more likely to be assaulted on the street by unknown men than in her } \\
\text { own home by her husband }\end{array}$ & True & 1 \\
\hline b & GBV is very rare among women seeking health services at health institutions & False & 1 \\
\hline c & $\begin{array}{l}\text { Domestic violence affects all sectors of society irrespective of social, economic, } \\
\text { cultural and religious values }\end{array}$ & True & 1 \\
\hline d & $\begin{array}{l}\text { Most women victims of GBV would not disclose GBV as the source of their injuries } \\
\text { to Health Care Providers }\end{array}$ & True & 1 \\
\hline e & $\begin{array}{l}\text { It is mandatory for Health professionals to report identified cases of GBV to police } \\
\text { f }\end{array}$ & $\begin{array}{l}\text { Victims of GBV are required to obtain a police medical report form (medico-legal } \\
\text { examination report form) from the police or ASAZA before provision of medical } \\
\text { services (except in emergencies). }\end{array}$ & True \\
\hline g & $\begin{array}{l}\text { It is the role and responsibility of Health professionals to enquire about gender based } \\
\text { violence where the victim tries to conceal it. }\end{array}$ & False & 1 \\
\hline h & $\begin{array}{l}\text { Clinical care for survivors of GBV require Health care Professionals to obtain an } \\
\text { informed consent from victims for any notifications or referral }\end{array}$ & True & 1 \\
\hline
\end{tabular}

\section{Cut off points for levels of knowledge}

Low levels of Knowledge: 1 - 4 scores

high levels of knowledge: $5-8$ scores

Appendix VI: score sheet for health professionals screening practices

\begin{tabular}{|l|l|}
\hline Screened clients & Scores \\
\hline Yes & 1 \\
\hline No & 0 \\
\hline Maximum score & $\mathbf{1}$ \\
\hline Type of screening & \multicolumn{2}{|l|}{} \\
\hline Part of routine history & 3 \\
\hline Upon suspicion for GBV & 2 \\
\hline Self-disclosure/ other & 1 \\
\hline Maximum score & $\mathbf{3}$ \\
\hline Frequency of GBV screening \\
\hline Never & 0 \\
\hline Rarely / A few times & 1 \\
\hline Often / Very often & 2 \\
\hline Maximum score & $\mathbf{2}$ \\
\hline Total screening practice score & $\mathbf{6}$ \\
\hline
\end{tabular}

Appendix-VII: Score sheet for Health professionals'
reporting practices
\begin{tabular}{|l|l|}
\hline Reports GBV & Scores \\
\hline Yes & 1 \\
\hline No & 0 \\
\hline Maximum score & 1 \\
\hline Type of reporting & 3 \\
\hline Mandatory & 2 \\
\hline Voluntary & 1 \\
\hline Other & $\mathbf{3}$ \\
\hline Maximum score & 0 \\
\hline Frequency of GBV reporting & \\
\hline Never & 1 \\
\hline Rarely / A few times & 2 \\
\hline Often / Very often & $\mathbf{2}$ \\
\hline Maximum score & $\mathbf{6}$ \\
\hline Total reporting practices score & $\mathbf{1}$ \\
\hline
\end{tabular}

